\title{
Origin of the Bulletin of Environmental Contamination and Toxicology
}

\author{
John Hylin ${ }^{1}$
}

Received: 21 December 2015/ Accepted: 6 January 2016/Published online: 21 January 2016

(C) Springer Science+Business Media New York 2016

One morning in the Spring of 1965, I stopped by the office of Francis Gunther at the University of California, Riverside for a cup of coffee, as I often did. I had been invited by Gunther to spend my first sabbatical leave there after we had met as committeemen on the USDA Regional Project W-45, titled "Pesticide Residues". Gunther wanted my help in solving a vexing problem concerned with the analysis of organo-chlorine residues in crop samples.

Over coffee he explained another concern. As Editor of Residue Reviews, he was responsible for producing two volumes per year of the hard-covered book. Although he had enough articles in progress for 2-3 years, he was seeking a way to generate suitable manuscripts into the future.

At annual meetings of the Technical Committee of $\mathrm{W}-45$, participants expressed their difficulties in finding suitable scientific periodicals for publishing their articles. They were looking for an outlet to publish their research in what was a relatively new but growing field of environmental contamination by residues of agricultural chemicals and accompanying toxicological effects on non-target species, both animal and plant.

In discussions with the editorial office of SpringerVerlag in Heidelburg, the publisher of Residue Reviews, it was decided to consider two new scientific journals to provide an outlet for research related to the topics in Residue Reviews. One of the goals was to open the possibility for multiple publishing options with hopes that authors might also submit review articles in their fields as the result of literature searches for their own research.

\footnotetext{
John Hylin

jwhylin@aol.com

1 Incline Village, NV, USA
}

Further discussions resulted in tentative names for these proposed journals. One would be for short articles announcing recent discoveries in the field. This became the "Bulletin of Environmental Contamination and Toxicology". The second journal would be for follow-up fulllength articles describing in-depth studies based on Bulletin reports. This became the "Archives of Environmental Contamination and Toxicology".

In the fall of 1965, Gunther told me that Springer-Verlag was going ahead with these new journals and asked if I would consider being Editor-in-Chief of the Bulletin. I demurred but he persisted, stating that he had already started to establish an Editorial Board to assist me from his acquaintances in the field worldwide and our mutual colleagues in $\mathrm{W}-45$. He was very persuasive.

During the remaining months of 1965 and into the first half of 1966, the format of the Bulletin was developed. With guidance from Springer-Verlag, it was decided that there would be no page charges for authors. Also, articles were to be reproduced photographically from the original manuscripts. This required creating detailed Instructions to Authors as to specific requirements for the format of manuscripts. Manuscripts were to be limited to 8 pages. These would consist of a Title, Name(s) of Author(s) and Affiliation(s) (to be typeset by Springer-Verlag, to provide uniform presentation for articles with varying typefaces), Introduction, Materials and Methods or Experimental, Results and Discussion and a single page for References.

Initially there would be eight 8-page manuscripts for a total of 64 pages per bimonthly issue. The front cover would have the journal's name and would list the articles, plus a publisher's identification on the back cover. The inside front cover would have The Aims and Scope of the journal described and Instructions for Subscribing. The 
inside back cover would have the Instructions for Authors. The front and back covers would be in blue color.

During early 1966, back in my office at the University of Hawaii, Honolulu, I began accumulating, editing, returning manuscripts for revision, and compiling the first issues of the Bulletin. Camera-ready copies, including material to be typeset, were sent to Springer-Verlag, New York. The first issue appeared in the fall of 1966, with subsequent issues appearing every 2 months.

Early issues required extensive editing, including typing and retyping, cutting and pasting. Sometimes, extensive revision was necessary for bringing manuscripts into conformity with our Instructions to Authors format. As the Bulletin became more widely known during these early years, an increasing number of acceptable manuscripts arrived which required no format revision. Most authors willingly revised their manuscripts to comply with the Bulletin's format requirements. It is not surprising what authors can accomplish if they receive a returned manuscript accompanied by the statement." Your manuscript is accepted provided you change...".

Fifty years of publication is a measure of the value and success of the Bulletin of Environmental Contamination and Toxicology. I enjoyed the challenge of prepping the issues of the Bulletin during my tenure of 13 years. I wish the journal continued success for the next 50 years and beyond.

John Hylin, Editor-in-Chief (1966-1978) 